\title{
Desain Aplikasi Pengadaan Benih Ikan Di Balai Benih Ikan Kabupaten Morowali Berbasis Android
}

\author{
Citra Yustitya Gobel ${ }^{1}$, Santawali², Dewi Cahyani Mayang ${ }^{3}$ \\ ${ }^{1}$ e-mail: gobelcitra87@gmail.com, ${ }^{2}$ santawalisaid@gmail.com, ${ }^{3}$ dewi.mayang@gmail.com, \\ ${ }^{1}$ Teknik Elektro, Universitas Ichsan Gorontalo, \\ ${ }^{2}$ Sistem Informasi, Stmik Ichsan Gorontalo. \\ 4JILN *OCPSNBIJ 4UNJL *D TBO( PSPOBNA
}

\begin{abstract}
Korowalelo Fish Seed Hall (FSH) currently has 14 pond facilities consisting of 6 Maturation Ponds, 2 Spawning Tubs, 4 Larvae Pools and 2 Nursery Pools. Fish seeds that have been produced will be sold in general. However, Fish Seed Procurement Information at the North Morowali District Fish Seed Hall is still less known by the general public because of the location of the hall within the residential area of the residents and the Fish Seed Hall information dissemination system is asking other people. So the authors designed an android-based application that can facilitate the presentation of information to the general public and facilitate ordering fish seeds.Methods of analysis system used is the method waterfall with stages that is designing the system (system engineering), intensive interaction between systems analyst (Requirement Analysis), design (Design), pengkodingan (Coding), the execution of the program (Testing) maintenance (Maintenance).To test whether the application can run properly then do testing of white box and black box and it can be concluded that the results of the calculation Cyclematic Complexcity $(C C)$ is equal to $V(G)$ therefore it may be concluded that the system can run in effective and efficient. Implementation of the system applied to the android version 7.0 (Nougat), version 8.0 (Oreo), and version 6.0 (Marshmallow).
\end{abstract}

Keywords— Android, Information System, Fish Seed Hall, web service.

Intisari- Balai Benih Ikan (BBI) Korowalelo saat ini memiliki 14 Fasilitas kolam yang terdiri dari 6 Kolam Pematangan, 2 Bak Pemijahan, 4 Kolam Larva dan 2 Kolam Pendederan. Benih ikan yang telah dihasilkan akan dijual secara umum. Namun Informasi Pengadaan Benih Ikan di Balai Benih Ikan Kabupaten Morowali Utara ini masih kurang diketahui oleh masyarakat umum karena lokasi Balai yang berada didalam wilayah perumahan warga dan sistem penyebaran informasi Balai Benih Ikan yaitu bertanya kepada orang lain. Sehingga penulis merancang sebuah aplikasi berbasis android yang dapat memudahkan penyajian informasi kepada masyarakat umum serta mempermudah pemesanan benih ikan.Metode analisis sistem yang digunakan adalah metode waterfall dengan tahapan yaitu perancangan sistem (system engineering), interaksi intensif antar analis sistem (Requirement Analysis), desain (Design), pengkodingan (Coding), eksekusi program (Testing), pemeliharaan (Maintenance).Untuk menguji apakah aplikasi dapat berjalan dengan baik maka dilakukan pengujian white box dan black box dan dapat disimpulkan bahwa hasil perhitungan Cyclematic Complexcity (CC) sama dengan V (G) karena itu dapat disimpulkan bahwa sistem dapat berjalan secara efektif dan efisien.Implementasi sistem diterapkan pada android versi 7.0 (Nougat), versi 8.0 (Oreo), dan Versi 6.0 (Marshmallow

\section{Kata Kunci-Android, Sistem Informasi,Balai Benih Ikan,web service}

\section{PENDAHULUAN}

Perkembangan teknologi yang sangat cepat telah membawa manusia memasuki kehidupan yang berdampingan dengan informasi dan teknologi itu sendiri yang berdampak pada sebagian orang untuk meninggalkan proses penelusuran informasi secara manual yang membutuhkan waktu lebih lama untuk mendapatkan atau menemukan informasi yang diinginkan. Teknologi informasi yang telah berkembang saat ini dapat mengelolah informasi yang dilakukan secara lebih aktual dan optimal. Penggunaan teknologi informasi bertujuan untuk mencapai efisiensi dalam berbagai aspek pengelolaan informasi, yang ditunjukkan dengan kecepatan dan ketepatan waktu pemrosesan, serta ketelitian dan keakuratan informasi. Hal ini mengakibatkan dalam pengembangan sistem informasi muncul variasi baru [1].

Pasokan ikan dunia saat ini sebagian besar berasal dari hasil penangkapan ikan di laut. Namun demikian pemanfaatan sumberdaya tersebut di sejumlah negara dan perairan internasional saat ini berlebih. Oleh karena itu, alternatif pemasok hasil perikanan diharapkan berasal dari pembudidayaan ikan [2]. Untuk mendukung pembudidayaan ikan di Kabupaten Morowali Utara, Pemerintah telah menyediakan Balai Benih Ikan yang terletak di Desa Korowalelo. Balai Benih Ikan (BBI) Korowalelo saat ini memiliki 14 Fasilitas kolam yang terdiri dari 6 Kolam Pematangan, 2 Bak Pemijahan, 4 Kolam Larva dan 2 Kolam Pendederan. Selain itu BBI.

Korowalelo memiliki 2 fasilitas bangunan Gudang dan Pakan, kantor dan rumah jaga yang digunakan oleh petugas/staf BBI. Produksi Benih Ikan yang dihasilkan pada tahun 2019 adalah 17.000 ikan nila dan 900 ekor ikan mas. Benih ikan yang telah dihasilkan akan dijual secara umum. Namun Informasi Pengadaan Benih Ikan di Balai Benih Ikan Kabupaten Morowali 
Utara ini masih kurang diketahui oleh masyarakat umum karena lokasi Balai yang berada didalam wilayah perumahan warga dan sistem penyebaran informasi Balai Benih Ikan yaitu bertanya kepada orang lain. Tentunya hal ini membuat pemasaran balai benih ikan menjadi sepi pembeli. Hasilnya Balai Benih Ikan sulit untuk menambah pengadaan benih ikan karena kurang hasil penjualan benih ikan.

Di Kabupaten Morowali Utara, Masyarakat yang ingin membeli benih ikan langsung mendatangi Balai Benih Ikan dan melihat langsung benih ikan yang tersedia. Sistem yang diterapkan masih konvensional yaitu memberikan uang secara langsung kemudian pihak balai memberikan nota atau kuitansi untuk ditanda tangani sebagai legalitas pembelian benih ikan. Pada tahun 2019 benih yang terjual untuk ukuran $3-5 \mathrm{~cm}$ yaitu 15.000 ekor dengan harga Rp.500,- per ekor dan untuk ukuran $5-8 \mathrm{~cm}$ yaitu 5.000 ekor dengan harga Rp.1000,- per ekor

Penggunaan smartphone android yang telah meluas dikalangan masyarakat menuntut Balai Benih Ikan Morowali Utara untuk dapat menyediakan sistem informasi yang dapat meningkatkan sistem penyebaran informasi pengadaan benih ikan yaitu dengan memanfaatkan Internet sehingga segala informasi tentang pengadaan benih ikan di Balai Benih Ikan Morowali Utara dapat dilihat secara real-time melaui smartphone android. Dengan alasan dan uraian ini, maka penulis merancang sebuah aplikasi dalam sebuah penyusunan Tugas Akhir yang berjudul "Aplikasi Pengadaan Benih Ikan Di Balai Benih Ikan Kabupaten Morowali Utara Berbasis Android".

\section{TUJUAN PENELITIAN}

Adapun tujuan dari penelitian yaitu membuat sistem informasi yang dapat memudahkan pihak Balai Benih Ikan Morowali Utara untuk menyebarkan informasi pengadaan benih ikan yaitu dengan memanfaat internet sehingga masyarakat dapat dengan mudah mengetahui perkembangan informasi pengadaan benih ikan melalui smartphone android.

\section{METODE PENELITIAN}

Penelitian ini menggunakan metode Research and Development atau yang dikenal dengan metode Penelitian dan Pengembangan. Metode ini didefinisikan sebagai metode penelitian yang digunakan untuk menghasilkan produk tertentu dan menguji keefektifan produk tersebut.. Sejalan dengan hal tersebut, Sudaryono mendefinisikan penelitian dan pengembangan sebagai suatu proses pengumpulan dan analisis data dilakukan secara sistematis dan logis untuk mecapai tujuan tertentu. Research and Development membagi metode menjadi 3 bagian dalam penelitian yaitu :

a. Deksriptif. Digunakan dalam studi awal untuk menghimpun data kondisi yang ada yaitu perbandingan kondisi produk yang sudah ada dan yang akan dikembangkan, kondisi pihak pengguna, kondisi faktor pendukung dan penghambat.

b. Evaluatif. Digunakan untuk mengevaluasi proses uji coba pengembangan suatu produk.

c. Eksperimen. Digunakan untuk menguji keampuhan produk yang dihasilkan.

Metode Research and Development digunakan peneliti untuk membangun sistem informasi penjualan berbasis Android..

\section{a. Identifikasi Masalah}

Penyebab Permasalahan, seperti yang telah bahas di atas yaitu Informasi Pengadaan Benih Ikan di Balai Benih Ikan Kabupaten Morowali Utara masih kurang diketahui oleh masyarakat umum karena lokasi Balai yang berada didalam wilayah perumahan warga dan sistem penyebaran informasi Balai Benih Ikan yaitu dari mulut ke mulut. Memahami kerja sistem yang ada merupakan hal penting yang wajib untuk dilaksanakan. Tujuan dari memahami kerja sistem yang berjalan yaitu untuk mencari permasalahan - permasalahan yang ada pada sistem yang lama. Berdasarkan hasil penelitian yang dilakukan ditemukan beberapa variabel - variabel yang menjadikan permasalahan dan akan ditemukan solusi pada sistem yang diusulkan.

\section{b. Jenis dan Sumber Data}

1. Data primer diperoleh dari sumber primer, dimana peneliti secara langsung melakukan observasi atau penyaksian kejadian-kejadian yang dituliskan. Data Primer, data primer dipandang memiliki otoritas sebagai bukti tangan pertama dan diberi otoritas dalam pengumpulan data, dalam hal ini melakukan wawancara langsung dengan pihak yang terkait. Data primer dalam penelitian ini yaitu segala data yang ditemui pada saat observasi di lokasi penelitian.

2. Data Sekunder, data sekunder diperoleh dari sumber sekunder, yaitu penulis mengumpulkan data-data dan referensi yang dibutuhkan untuk menyempurnakan penulisan proposal ini, contohnya yaitu referensi jurnal tentang teknik perancangan dan pengembangan aplikasi pemasaran.

\section{c. Metode Pengumpulan Data}

Teknik pengumpulan data dilakukan dengan cara:

1. Observasi, teknik ini dilakukan dengan melakukan pengamatan langsung di tempat penelitian. 
2. Interview, pengumpulan data dengan cara tatap muka dan tanya jawab langsung dengan sumber data, yaitu kepada Bapak David M. Tungka, S.Pi. Beliau selaku Pimpinan Balai Benih Ikan Korowalelo.

\section{ANALISIS DAN DESAIN SISTEM}

\section{Analisa Sistem yang diusulkan}

Sistem yang diusulkan digambarkan dengan usecase diagram di bawah ini.

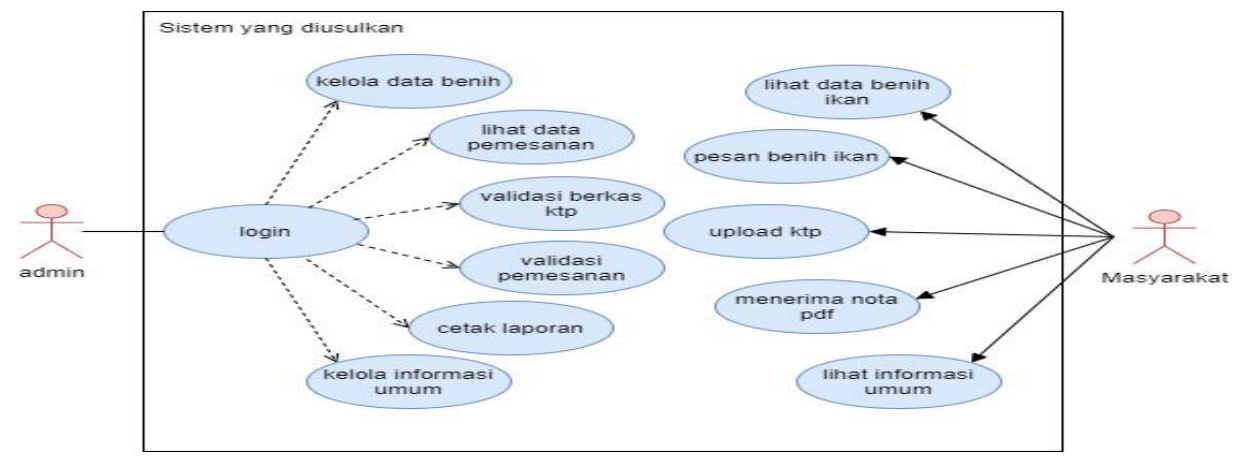

Gambar 1 Sistem yang diusulkan

Berdasarkan gambar di atas di jelaskan bahwa admin melakukan login kemudian dapat mengelola data benih, melihat data pemesanan yang kemudian dilakukan validasi ktp dan validasi pemesanan. Admin juga dapat mencetak laporan dan mengelola informasi umum. Selanjutnya aktor masyarakat melalui smartphone android dapat melihat data benih ikan berupa nama jenis benih ikan, asal benih, harga dan stok benih. Jika memesan benih ikan harus mengisi formulir pemesanan serta mengupload foto KTP. Jika berhasil melakukan pemesanan masyarakat akan menerima nota dalam bentuk pdf yang nantinya akan dibawa ke balai. Selanjutnya untuk informasi umum bisa dilihat pada menu info umum

\section{Tampilan Aplikasi}

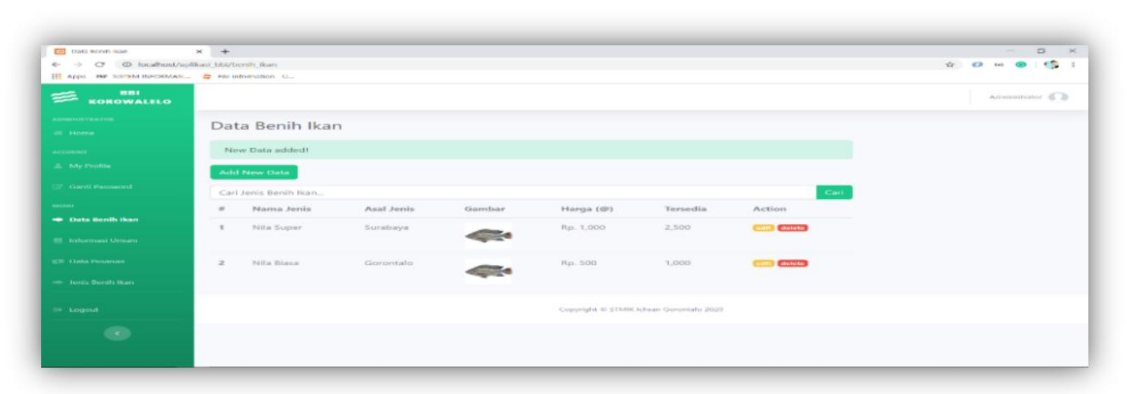

Gambar 2. GUI data Benih Ikan 


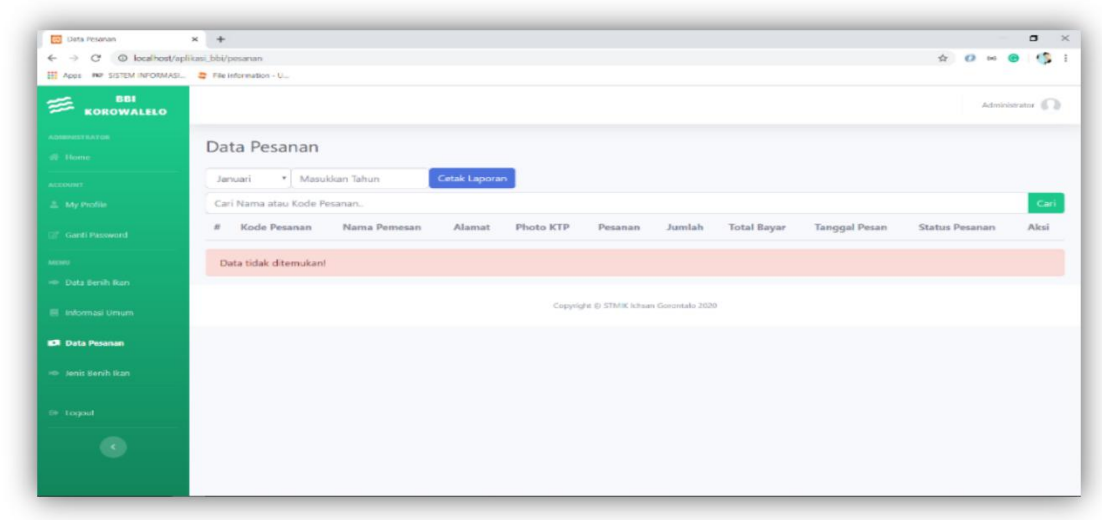

Halaman ini menampilkan data benih ikan. Data ini dapat kelola penuh oleh Administrator.

\section{Gambar 3. Halaman Data Pesanan}

Halaman ini menampilkan data Informasi Umum. Pada halaman ini, Administrator dapat melakukan validasi yaitu validasi berkas dan validasi pembayaran pesanan.

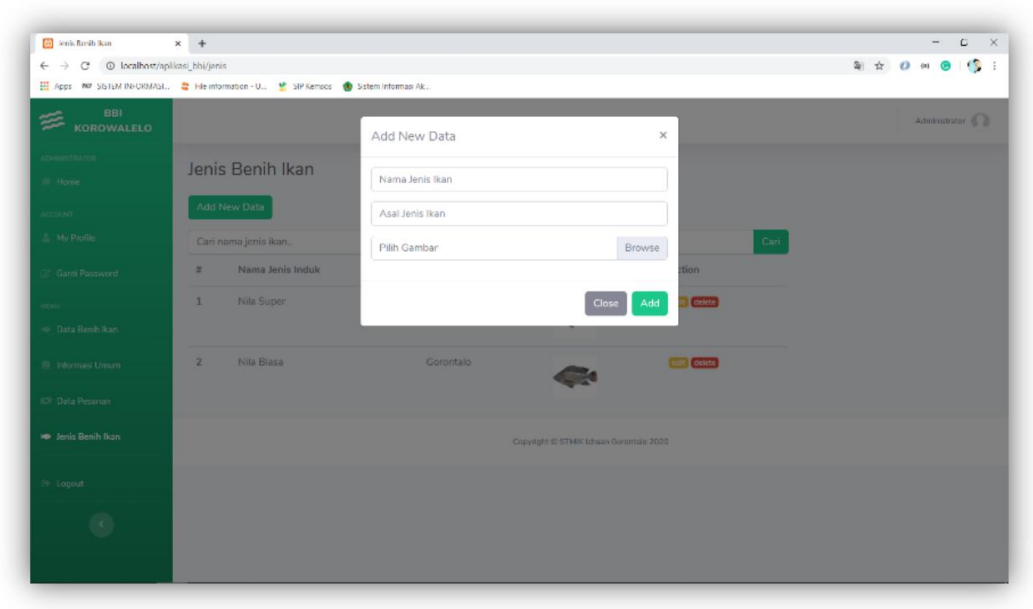

Gambar 4. Halaman Data Pesanan

Halaman ini menampilkan data Informasi Umum. Pada halaman ini, Administrator dapat melakukan validasi yaitu validasi berkas dan validasi pembayaran pesanan
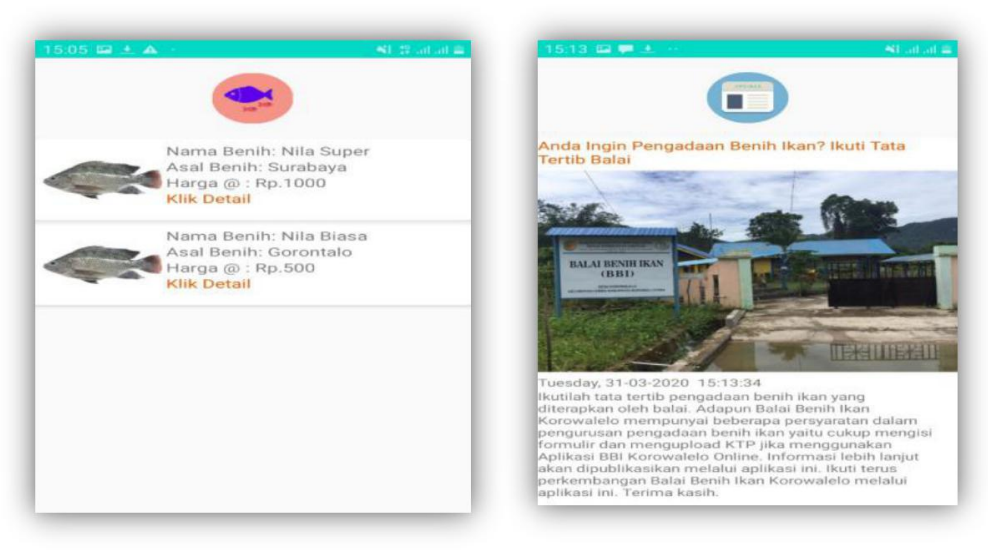

Gambar5.. Halaman Benih Ikan dan Informasi Umum 
Gambar di atas adalah tampilan untuk halaman benih ikan dan informasi umum. Pada halaman benih ikan menampilkan benih ikan yang tersedia. Dan halaman informasi umum menyajikan informasi aktual dari Balai Benih Ikan Korowalelo.
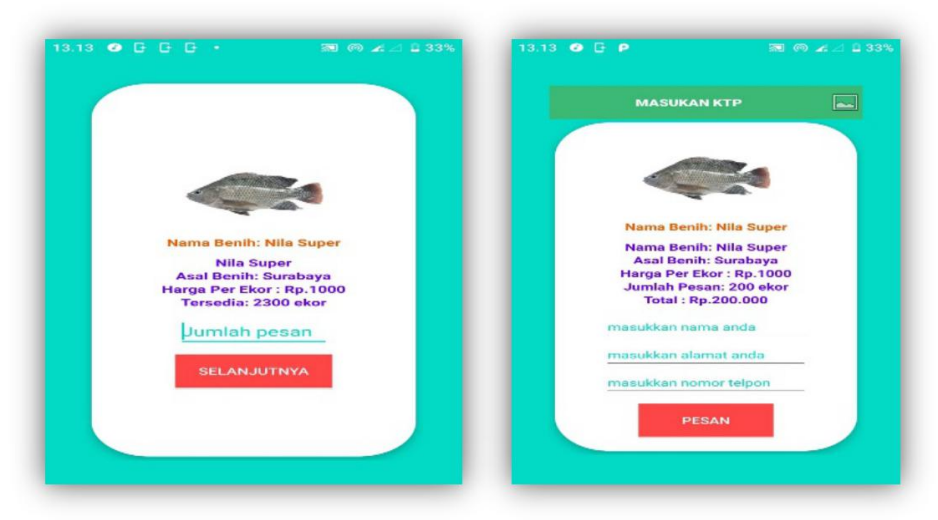

Gambar 6. Halaman Pesan Benih dan Isi Formulir Pesanan

Gambar di atas adalah tampilan halaman pesan benih yang digunakan untuk memesan jumlah benih. Selanjutnya mengisi formulir pesanan dengan melengkapi form dan memasukkan foto KTP.
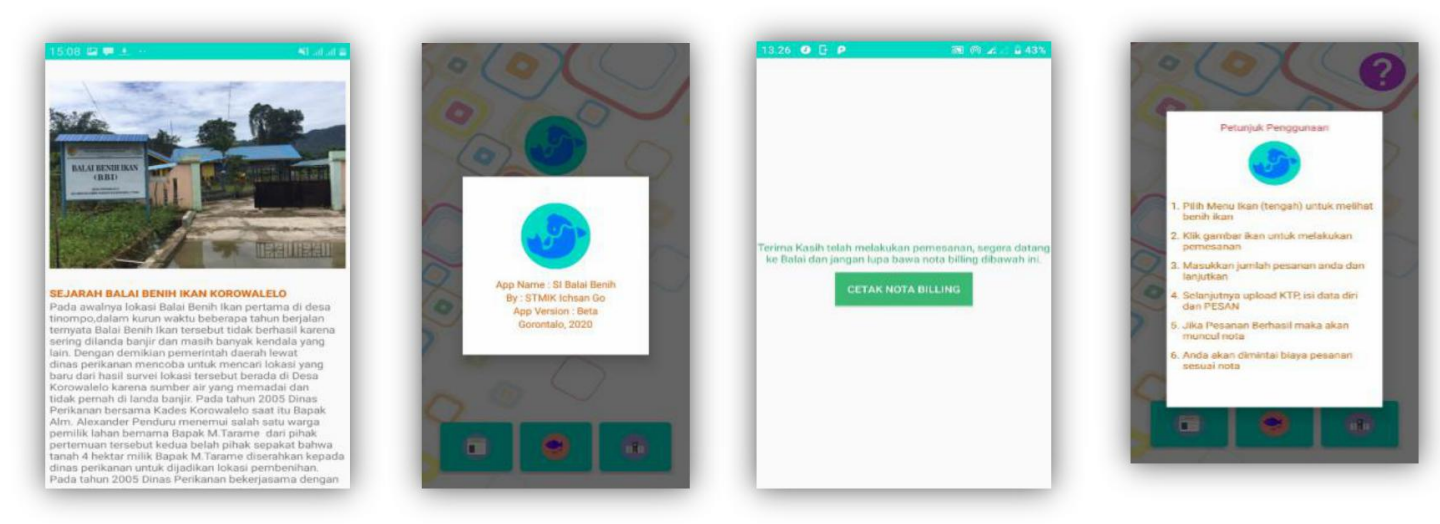
Gambar di atas adalah tampilan dari halaman cetak billing, dimana halaman ini akan tampil setelah user berhasil melakukan pemesanan benih ikan. Kemudian halaman bantuan menampilkan popup petunjuk penggunaan aplikasi agar dapat memudahkan bagi user baru.

\section{KESIMPULAN}

Dari hasil penelitian di atas maka ditemukan beberapa hal sebagai kesimpulan, yaitu:

1. Sistem yang telah dibuat mampu memberikan kemudahan untuk mendapatkan informasi mengenai pengadaan benih ikan yang ada di Balai Benih Ikan Desa Korowalelo Kabupaten Morowali Utara.

2. Dengan adanya sistem ini masyarakat yang ingin melakukan pemesanan benih ikan sudah bisa dari rumah cukup dengan menggunakan Smartphone android dan jaringan internet.

\section{SARAN}

Saran untuk pengembangan penelitian ini adalah sebagai berikut:

1. Untuk pengembangan aplikasi nanti sebaiknya sistem ini dapat dikembangkan pada sistem operasi lainnya seperti mac os.

2. Penambahan proses chating, sehingga masyarakat dapat berinteraksi langsung dengan pihak balai.

3. Pengembangan aplikasi dengan fitur menu metode pembayaran paypal

\section{REFERENSI}

[1] Ridwan,” Pengantar Tekhnologi Informasi,” Jakarta: Gramedia, 2008.

[2] F. M. Sukadi, "Peningkatan Teknologi Budidaya Ikan," Jurnal Iktiologi Indonesia, vol. II, pp. 61-66, 2002.

[3] D Radike, "Sistem Informasi Pengolahan Data Produksi Ikan Pada Kantor Balai Benih Ikan (BBI) Talang Kemulun Menggunakan Bahasa Pemrograman VB. NET (Studi Kasus Pada Kantor Balai Benih Ikan (BBI) Talang Kemulun)," Jurnal Sekolah Tinggi Manajemen Informatika dan Komputer GICI (JURSIMA), vol. VII, 2019.

[4] P. Yan, "Rancang Bangun Aplikasi E-Marketing untuk Pemasaran Benih Ikan Berbasis Web (studi Kasus GAPOKDAKAN Mitra Jaya)," Institutional Repository Universitas Teknokrat Indonesia, 2018.

[5] F. Nurpandi and H. Kurniawan, "Sistem Informasi Pembudidayaan Ikan di Balai Pelestarian Perikanan Perairan Umum Dan Pengembangan Ikan Hias (BPPPUIH) Ciherang - Cianjur," Media Jurnal Informatika, vol. VIII, 2016

[6] A. Kadir, Pengenalan Sistem Informasi, Edisi Revisi ed., D. H, Ed., Yogyakarta: Andri Yogyakarta, 2014

[7] D. Darmawan and K. Fauzi Nur, Sistem Informasi Manajemen, Bandung: PT. Remaja Rosdakarya, 2013.

[8] . \&. Schooner, Incrementalism Eroding the Impediment to a Global Public Procurement Market, Journal Of Internasional Law, 2007.

[9] . P. Jati Arsana, Manajemen Pengadaan Barang dan Jasa Pemerintah, Yogyakarta: CV Budi Utama, 2016.

[10] C. Purbomartono, M. D.S and E. Rochmawati, "Identifikasi Ektoparasit Protozoa Pada Benih Ikan Tawes di Balai Benih Ikan Sidabowa Kabupaten Banyumas dan Balai Benih Ikan Kutasari Kabupaten Purbalingga," Fakultas Perikanan dan Kelautan Universitas Muhammadiyah Purwokerto, 2006.

[11] I. D. M. Heryadi Sutisna and R. Sutarmanto, Pembenihan Ikan Air Tawar, Yogyakarta: Kanisius, 1995.

[12] N. Safaat, Pemrograman Aplikasi Mobile Smarphone dan Table PC Bebasis Android, Bandung: Informatika, 2012.

[13] . D. Kasman, Kolaborasi Dahsyat Android Dengan PHP \& MySQL, Yogyakarta: Lokomedia, 2003.

[14] R. Hakim and Sutarto, Mastering Java : Konsep Pemrograman Java dan Penerapannya untuk membuat Software Aplikasi, Jakarta: PT. Elex Media Komputindo, 2010.

[15] A. Kadir, Pemrograman Web : HTML, CSS, Javascript, dan PHP, Yogyakarta: Andi Offset, 2003. 
JTII, Vol. 5, No.2, November 2020

Desain Aplikasi Pengadaan...

ISSN 2502-1613/E-ISSN 2541-3740 